\title{
A simple descriptive analysis of hospital admissions' progress: a case study of the Greatest Public General Hospital, Athens, Greece
}

\author{
Zoe Boutsioli \\ Health Research Unit, Athens Institute for Education and Research (ATINER), Athens, Greece
}

Correspondence: Zoe Boutsioli. Address: Health Research Unit, Athens Institute for Education and Research (ATINER), 20 Omirou Street, Athens, Greece. Telephone: 30-697-080-6321. Fax: 30-210-361-8314. E-mail: zb5@atiner.gr

Received: May 23, 2012

DOI : $10.5430 /$ jha.v1n1p36
Published: September 1, 2012

URL: http://dx.doi.org/10.5430/jha.v1n1p36

\section{Abstract}

This paper studies the progress of hospital admissions over the time period 1995-2005 for the largest Greek general public hospital. Daily admissions data, disaggregated into elective and emergency were collected from the IT Department of the hospital. Great seasonality for hospital admissions was found. They reduce during weekends, the summer months and official holidays. Emergency admissions are at their peak in the beginning of the week and decline afterwards. During weekends, emergency admissions decrease by $25 \%$. The majority of hospital elective admissions enter into the hospital from Monday to Thursday. During Friday and weekends, elective hospital admissions fall sharply, by $63 \%$. However, on Sunday, they slightly increase. The mean number of total hospital admissions increased by $17 \%$ from 1995 to 2005 . This increase in total admissions results from the significant increase of elective admissions (by 56\%) and not from the emergency admissions that fell by $17 \%$.

\section{Key words}

Emergency admissions, Greece, Seasonality, Public hospital

\section{I ntroduction}

On European Union (EU) level, the number of acute care hospital admissions has decreased over the last fifteen years. However, in Greece, the number of acute care hospital admissions per 100 persons has continuously increased up to $1998^{[1]}$.

The basic reasons for the high demand for hospital care, such as the gap of primary care and GPs, the ageing of the population, the health status and the new epidemiological status all exist in high rates in Greece.

First, in Greece there are a few general practitioners (GPs) and a limited system of primary health care ${ }^{[2]}$. Conversely, a great number of specialist doctors exist in Greece, i.e. 174/100,000 against 72/100,000 in EU-27 (EU-27: The European Union comprises the following 27 countries: Austria, Belgium, Bulgaria, Cyprus, Czech Republic, Denmark, Estonia, Finland, France, Germany, Greece, Hungary, Ireland, Italy, Latvia, Lithuania, Luxembourg, Malta, Netherlands, Poland, Portugal, Romania, Slovak Republic, Slovenia, Spain, Sweden, United Kingdom. Source: http://stats.oecd.org), in 
$2008^{[1]}$. This practically demonstrates the inexistence of any 'reference' or referral system from general to specialist doctors and in secondary and tertiary health care ${ }^{[3]}$. This situation leads patients either to Accident and Emergency departments ${ }^{[4]}$, or to Outpatient departments of hospitals to be seen by a doctor. This process makes their admission to hospital easier.

Second, the ageing of the population that concerns all western countries seems to have considerable effect on health care systems. In Greece, people aged over 65 are projected to be about 3.5 million in 2060, compared to 2.1 million in 2008. In other words, there will be an increase of 68\%, while the young (aged 1-14) and productive people (aged 15-64) are projected to decrease by $10 \%$ and $18 \%$ respectively ${ }^{[5]}$.

Third, the high level of obesity and the reduction in the 'Mediterranean diet', of which Greece was the most representative example a few years ago, has led to bad health for the Greeks over the last decades ${ }^{[6,7]}$.

The health status and the way of life are the main reasons that increase demand for health care in general and hospital care in particular. The number of people aged 15 and over as a percentage of the total population that smoke was $38 \%$ in 1998-2001, which is the highest percentage in the EU-15 (EU-15: Was the number of member countries in the European Union prior to the accession of ten candidates countries on 1 May 2004. The EU-15 comprised the following 15 countries: Austria, Belgium, Denmark, Finland, France, Germany, Greece, Ireland, Italy, Luxembourg, Netherlands, Portugal, Spain, Sweden, and United Kingdom. Source: http://stats.oecd.org) and the second highest in the EU-27 ${ }^{[8]}$. The mortality rate from car accidents and cardiovascular diseases per 100,000 people in 1999-2001 was the highest among the EU-15 and EU-27 ${ }^{[8]}$.

Fourth, environmental factors are also very prominent a fact that worsens people's health and leads to increased hospitalizations ${ }^{[9,10]}$.

The aim of this paper is to present the progress of hospital admissions to the largest Greek general hospital, over the time period 1995-2005. The paper is organized into five sections including the Introduction. Section 2 describes the data sources. Section 3 discusses the results. Section 4 discusses the policy implications, and Section 5 concludes.

\section{Methodology}

The progress of patients' admissions to the Athenian Hospital is assessed in the present study. The time period examined starts in 1/1/1995 and ends in 31/12/2005. Daily admissions data, disaggregated into elective and emergency data, were collected from the IT Department of the hospital. The classification of hospital admissions into 'elective' or 'emergency' is done by physicians, based on their scientific knowledge and clinical experience and not based on evidence-based medicine ${ }^{[11]}$. In our sample are included all admissions, independently of their length of stay.

\section{Results}

\subsection{Descriptive analysis}

Table 1. Descriptive statistics of admissions, 1995-2005

\begin{tabular}{llll}
\hline & Elective admissions & Emergency admissions & Total admissions \\
\hline Mean & 43 & 70 & 113 \\
Median & 42 & 34 & 94 \\
Maximum & 123 & 280 & 318 \\
Std. Dev. & 26 & 77 & 73 \\
Asymmetry & 0.1890 & 1.1066 & 0.8458 \\
Kurtosis & 2.1441 & 2.7869 & 2.8763 \\
\hline
\end{tabular}


On average, the hospital admitted 113 patients per day, 2/3 of which were emergency and 1/3 elective admissions. However, the hospital had admitted up to four times more emergency admissions on a typical day in relation to the mean value (Table 1). The high extreme (maximum) value and the high variability, mainly in the emergency admissions category, have been proved to cause high operational costs ${ }^{[12,13]}$. Thus, the accurate forecasting of future hospital admissions could assist hospitals to reduce operational costs ${ }^{[13,14]}$.

Daily admissions to the hospital face great seasonality. They reduce systematically during the summer months, official holidays and weekends (Figure 1). Particularly, Figure 1a shows the progression of hospital admissions per day of the week. Emergency admissions are at their peak in the beginning of the week and decline afterwards. During weekends, emergency admissions decrease by $25 \%$. The majority of hospital elective admissions enter into the hospital from Monday to Thursday. During Friday and weekends, elective hospital admissions fall sharply, by 63\%. However, on Sunday, they slightly increase. This could be attributed to a well-known practice of Greek hospital physicians to admit their patients on Sunday in order to ensure a hospital bed.

Figure $1 \mathrm{~b}$ depicts the behaviour of admissions to the hospital per month. The mean daily admissions, both emergency and elective, decrease during the months of December and January (Christmas holidays), April (Easter holidays) and July and August (summer vacations).

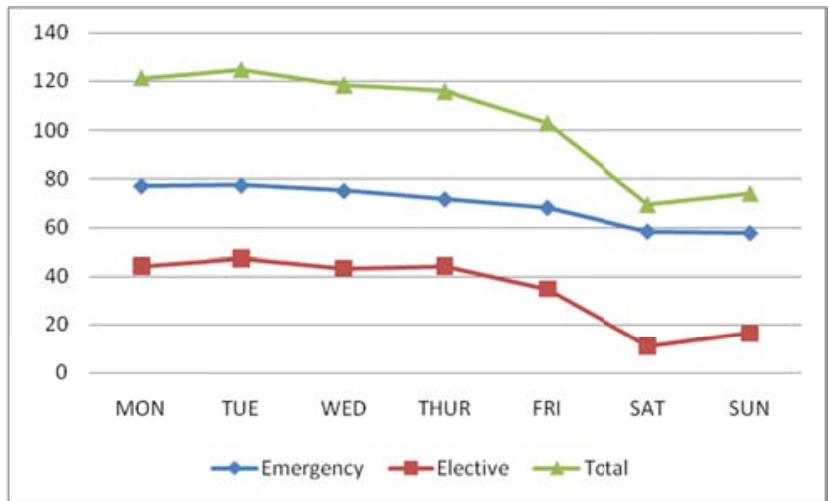

a) per day

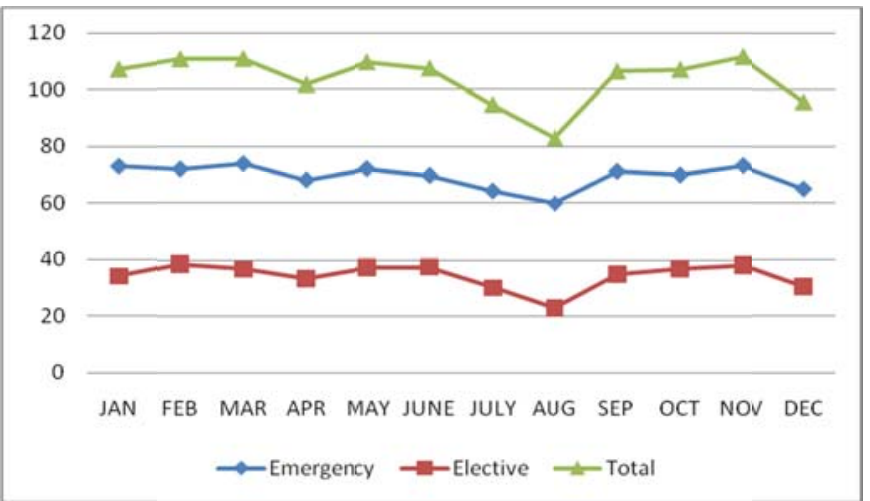

b) per month

Figure 1. Mean daily admissions a) per day and b) per month, 1995-2005

It can be concluded that part of emergency admissions are not actual 'emergency cases', since they follow a predicted path, as elective admissions. The phenomenon of non-emergency patients admitted to hospital as emergency cases on 'duty' days is a well-known situation to anyone who relates to hospital admissions, such as the Ministry of Health, hospital administrations and hospital staff. In the following section of this paper, this phenomenon is discussed in more detail.

\subsection{The progress of hospital admissions}

As seen in Figure 2, mean daily emergency admissions decreased by 17\% and in particular from 69 in 1995 to 57 in 2005. By year to year analysis, it is noticed that emergency admissions remain almost stable to 68-69 admissions from 1995 to 1997. In 1998 a small increase is observed by 7\% with emergency admissions reaching 74. On the contrary, in 1999 the mean daily emergency admissions declined, reaching 66 hospital admissions (an 11\% fall). From 2000 to 2003 the average daily emergency admissions increased constantly by 15\%. In particular, they rose from 66 in 2000 to 76 in 2003 . For the last two years of the analysis, what we see is a sharp fall of emergency daily admissions (by 25\%) to the hospital. In 2004, they reached 69 admissions and in 2005 they further fell to 57 admissions.

On the contrary, the mean daily elective admissions to the hospital reflect a stable increasing trend over the 10-year period (Figure 2). In particular, they increased from 23 admissions in 1995 to 52 admissions in 2005 or by 56\% within 10 years. 
Total admissions show an increase by 17\% from 1995 to 2005 (Figure 2). They rose from 91 admissions in 1995 to 109 admissions in 2005.

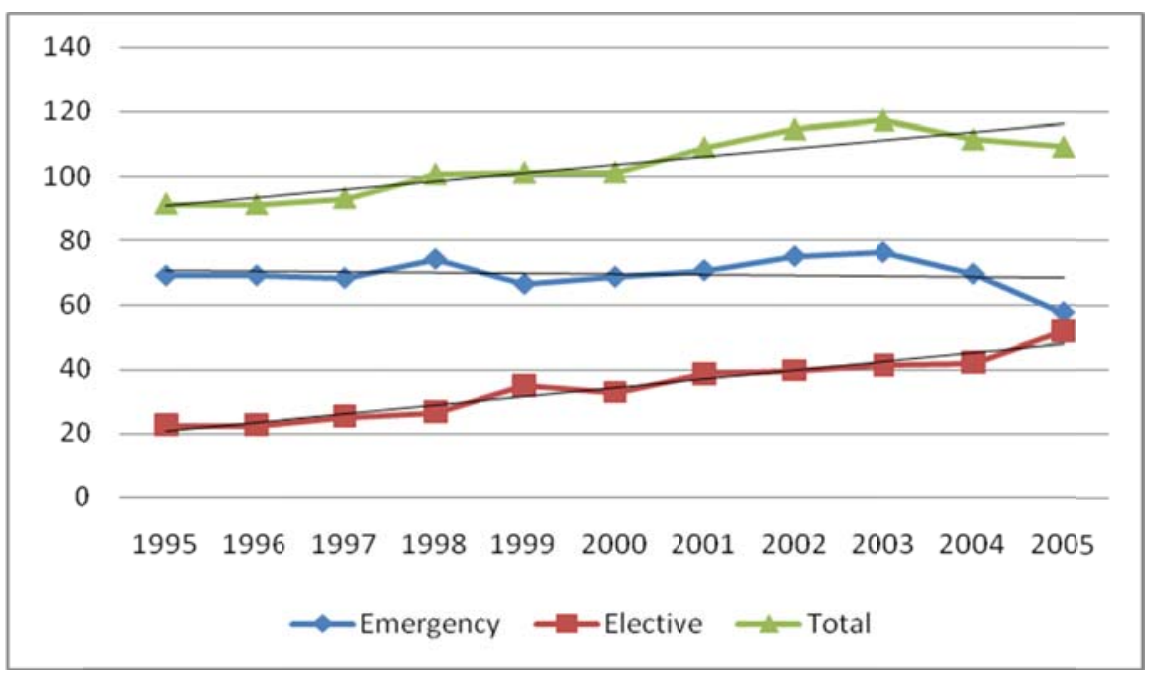

Figure 2. Progress of mean daily admissions, 1995-2005

\section{Discussion}

From the above analysis it is concluded that the mean number of total hospital admissions to the largest Greek hospital increased by $17 \%$ from 1995 to 2005 . This increase in total admissions results from the significant increase of elective admissions (by 56\%) and not from the emergency admissions that fell by $17 \%$.

Both categories of hospital admissions, elective and emergency, demonstrate great seasonality. They reduce during weekends, the summer months and official holidays. This situation is logically explained and understood for elective admissions, due to their nature, but needs further explanations for emergency admissions. A reasonable explanation could be that not all emergency admissions are real emergency cases, and that a part of elective patients were admitted to hospital as emergency cases, through the Accident and Emergency Departments of hospitals, on 'duty' days. This is a common practice in the majority of public hospitals in Greece. Here, a point is raised: Does this practice improve the hospital's technical and economic efficiency? In studies that examine the technical and economic efficiency of public hospitals in Greece, it is concluded that the majority of public hospitals are under the Production Possibility Frontier and are also economically inefficient ${ }^{[15-17]}$.

For this practice to be implemented, a number of groups of people are involved, such as doctors, patients and hospital administrations and staff. On one hand, patients in consultation with their doctors agree to be admitted to hospital when this is on duty in order to avoid the long waiting list ${ }^{[18]}$. The only responsibility of the doctor is to find a hospital bed for his patient. On the other hand, hospital administrations try (or they should try) to fill up hospital beds, having a high capacity rate. According to $\mathrm{WHO}^{[1]}$, the capacity rate for acute care hospitals in Greece was $72 \%$, in 2005 , compared to $76 \%$ in the EU-15. At this point, someone could support that this is an effective practice for public hospitals in order to be more technical and cost efficient. However, how could this phenomenon work better without undermining the 'principle of equality'? Hospital administrations should make sure that on duty days of hospitals there are plenty of empty beds to cover both categories of patients admitted: (a) real emergency cases and (b) non-real emergency patients. Up until now, the Ministry of Health asks all public hospitals to keep $25 \%$ of their developed beds empty the day before they are on duty in order to meet unexpected demand. However, in practice, this measure is not formally taken, since doctors' power is greater than that of hospital managers. 
Therefore, other health policies are needed to ensure that both hospital efficiency and equality are met. The most recent health policy decision that has affected directly and/or indirectly the problem discussed here was enacted in 2004 by the

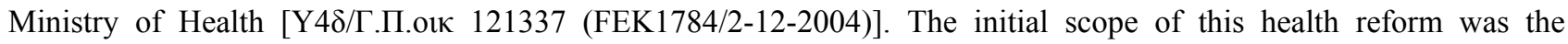
reorganization of hospital admissions resulting in the reduction of auxiliary beds in big hospitals in Athens. In practice, this could be done by changing their emergency services. All public hospitals in the greater region of Athens would be on duty for emergency services on a daily morning shift. Applying such a measure, the political leadership of the Ministry of Health wanted to reduce pressure on the big hospitals in Athens. Initially, it was applied on a pilot basis for 3 months. The results were considered to be in the right direction and the measure was globally applied. So far, there is not any official total evaluation of this health reform available. The only study that verifies the Ministry of Health's results is a PhD study that found that after the application of this measure, the number of emergency admissions have increased by $30 \%$ in small hospitals, while they have decreased by $20-25 \%$ in big hospitals, on average ${ }^{[13]}$, without validating if this has improved their technical and economic efficiency. The latter needs further research.

Other measures expected to result in the reorganization of hospital admissions among the public hospitals in the greater region of Athens include the decision for collaboration between public NHS hospitals and military hospitals, especially in the case of emergency services (Law 3868/2010). This could reduce the waiting time for elective services and improve the treatment for emergency cases, increasing the quality of the health care provided.

Finally, the health care reform that could radically change and improve the hospital admissions process in Greek public NHS hospitals is the organization of a well-developed, well-organized and well-managed primary health care service, which is totally missing. However, the last health reform with the establishment of EOPYY (Integrated Body for Health Care Services Provision) with the Law 3918 (FEK A'31/2-3-2011 \& FEK B' 2456/3-11-2011) is seems to be in the right direction. According to this organization, the great majority of direct and indirect insured people in Greece have equal access to primary services (i.e. GP's) and this newly created situation is expected to control the "free" access of people into hospitals and highly specialized care. Of course, the contribution of physicians is very important in the success of this health reform.

\section{Conclusion}

This study presents daily hospital admissions data of the greatest public NHS general hospitals in Greece and demonstrates their progress over the time period 1995-2005. We examine their progress in terms of three variables: weekend effect, summer holiday effect and official holiday effect. We have found that, on average, the hospital admitted 113 patients per day, $2 / 3$ of which were emergency and 1/3 elective admissions. Daily admissions to the hospital face great seasonality. They reduce systematically during the summer months, official holidays and weekends.

Mean daily emergency admissions decreased by $17 \%$ and in particular from 69 in 1995 to 57 in 2005 . On the contrary, the mean daily elective admissions to the hospital reflect a stable increasing trend over the 10 -year period. In particular, they increased from 23 admissions in 1995 to 52 admissions in 2005 or by $56 \%$ within 10 years. Total admissions show an increase by $17 \%$ from 1995 to 2005 . They rose from 91 admissions in 1995 to 109 admissions in 2005 .

The great seasonality of hospital admissions could easily be explained and understood for elective admissions but it is not "logical" for emergency admissions. This could be explained to the situation that part of emergency admissions are not actual 'emergency cases', since they follow a predicted path, as elective admissions. The political leadership of the Ministry of Health in accordance with other Ministries, hospital administrators, physicians and other hospital staff could work together in order to reduce this situation, resulting in greater efficiency of hospital care services, in Greece. 


\section{Acknowledgments}

The author would like to acknowledge the support provided by Professor Ann Netten, University of Kent, and Professor Alistair Gray, University of Oxford at various stages of its preparation. Mistakes and omissions remain the author's responsibility. Also, the author would like to thank the Greek Scholarship Foundation (IKY) for its financial support to her postgraduate studies. Finally, she would like to thank an anonymous referee for his/her contribution.

\section{References}

[1] WHO. WHO European Health for All Database. Copenhagen: WHO Regional Office for Europe; 2010.

[2] Tountas Y, Karnaki P, Pavi E. Reforming the reform: the Greek national health system in transition. Health Policy. $2002 ; 62: 15-29$. http://dx.doi.org/10.1016/S0168-8510(01)00217-2

[3] Mossialos E, Allin S, Davaki K. Analysing the Greek health system: A tale of fragmentation and inertia. Health Economics. 2005; 14: S151-S168. PMid:16161195 http://dx.doi.org/10.1002/hec.1033

[4] Triantafillou J, Mestheneos E. Pathways to care for the elderly in Greece. Social Science and Medicine. 1994; $38(7): 875-882$. http://dx.doi.org/10.1016/0277-9536(94)90421-9

[5] Przywara B. Projecting future health care expenditure at European level: drivers, methodology and main results. Economic Papers 417. Brussels: European Union; 2010.

[6] Bertsias G, Mammas I, Linardakis M, Kafatos A. Overweight and obesity in relation to cardiovascular disease risk factors among medical students in Crete, Greece. BMC Public Health. 2003; 3(3). http://dx.doi.org/10.1186/1471-2458-3-3

[7] Panagiotakos D, Pitsavos Chr, Chrysohoou Chr, Risvas Gr, Kontogianni MD, Zampelas A, Stefanadis Chr. Epidemiology of overweight in a Greek adult population: the Attica study. Obesity Research. 2004; 14: 1914-1920 PMid:15687390 http://dx.doi.org/10.1038/oby.2004.239

[8] Economou Ch. Health Policies in Greece and in European Countries. 1st ed. Athens: Dionicos; 2004 [in Greek].

[9] Pantazopoulou A, Katsouyanni K, Koureakremastinou J, Trichopoulos D. Short-term effects of air pollution on hospital emergency outpatient visits and admissions in the greater Athens, Greece area. Environmental Research. 1995; 69(1): 31-36. PMid:7588492 http://dx.doi.org/10.1006/enrs.1995.1022

[10] Atkinson RW, Anderson HR, Sunyer J, Ayres J, Boccini M, Vonk JM, Boumghar A, Forastiere F, Forsberg B, Touloumi G, Schwartz J, Katsouyanni K. Acute effects of particulate air pollution on respiratory admissions. American Journal of Respiratory and Critical Care Medicine. 2001; 164(10): 1860-1866. PMid:11734437

[11] Skalkidis Y, Nastos C, Zavitsanos X. Clinical protocols and clinical guidelines: Issues related to their applicability in everyday clinical practice. Archives of Hellenic Medicine. 2010; 27(2): 264-273.

[12] Hughes D, McGuire A. Stochastic Demand, Production Responses and Hospital Costs. Journal of Health Economics. 2003; 22(6): 999-1010. http://dx.doi.org/10.1016/S0167-6296(03)00048-1

[13] Boutsioli Z. Unexpected demand and its impact on hospital cost: the case of Greece. 1st ed. Athens: ATINER; 2009.

[14] Boutsioli Z. Forecasting the stochastic demand for inpatient care: the case of the Greek national health system. Health Services Management Research. 2010; 23(3): 116-120. PMid:20702888 http://dx.doi.org/10.1258/hsmr.2009.009025

[15] Giokas DI. Greek hospitals: how well their resources are used. Omega: The International Journal of Management Science. 2001; 29: 73-83.

[16] Athanassopoulos A, Gounaris Chr. Assessing the technical and allocative efficiency of hospital operations in Greece and its resource allocation implications. European Journal of Operational Research. 2001; 133: 416-431. http://dx.doi.org/10.1016/S0377-2217(00)00180-6

[17] Athanassopoulos AD, Gounaris Chr, Sissouras A. Health Care Management Science. 1999; 2: 97-106. PMid:10916606 http://dx.doi.org/10.1023/A:1019023408924

[18] Liaropoulos L, Siskou O, Kaitelidou D, Thoedorou M, Katostaras Th. Informal payments in public hospitals in Greece. Health Policy. 2008; 87(1): 72-81. PMid:18249459 http://dx.doi.org/10.1016/j.healthpol.2007.12.005 